\title{
Changes in suicide rates in disaster-stricken areas following the Great East Japan Earthquake and their effect on economic factors: an ecological study
}

\author{
Masatsugu Orui $\cdot$ Shuichiro Harada $\cdot$ \\ Mizuho Hayashi
}

Received: 12 May 2014/ Accepted: 1 September 2014/Published online: 22 October 2014

(c) The Japanese Society for Hygiene 2014

\begin{abstract}
Objective Devastating disasters may increase suicide rates due to mental distress. Previous domestic studies have reported decreased suicide rates among men following disasters. Few reports are available regarding factors associated with disasters, making it difficult to discuss how these events affect suicide rates. This study aimed to observe changes in suicide rates in disaster-stricken and neighboring areas following the Great East Japan Earthquake, and examine associations between suicide rates and economic factors.

Methods Monthly suicide rates were observed from March 2009 to February 2013, during which time the earthquake occurred on March, 2011. Data were included from disaster-stricken (Iwate, Miyagi, and Fukushima Prefectures) and neighboring (control: Aomori, Akita, and Yamagata Prefectures) areas. The association between changes in suicide rates and economic variables was evaluated based on the number of bankruptcy cases and ratio of effective job offers.

Results In disaster-stricken areas, post-disaster male suicide rates decreased during the 24 months following the earthquake. This trend differed relative to control areas. Female suicide rates increased during the first seven months. Multiple regression analysis showed that bankruptcy cases $(\beta=0.386, p=0.038)$ and ratio of effective job offers $(\beta=-0.445, p=0.018)$ were only significantly associated with male post-disaster suicide rates in control areas.
\end{abstract}

M. Orui $(\bowtie) \cdot$ S. Harada $\cdot$ M. Hayashi

Sendai City Mental Health and Welfare Center, 1-6

Sankyozawa, Aramaaki, Aoba-ku, Sendai 980-0845, Japan

e-mail: masatsugu_orui@city.sendai.jp
Conclusion Post-disaster suicide rates differed by gender following the earthquake. Our findings suggest that considering gender differences might be important for developing future post-disaster suicide prevention measures. This ecological study revealed that increasing effective job offers and decreasing bankruptcy cases can affect protectively male suicide rates in control areas.

Keywords Disaster $\cdot$ Earthquake $\cdot$ Suicide . Socioeconomic $\cdot$ Epidemiology

\section{Introduction}

The Great East Japan Earthquake occurred on March 11, 2011, with a magnitude of 9.0 and an epicenter approximately $130 \mathrm{~km}$ off the shore of Sanriku and east-southeast of the Ojika Peninsula. This earthquake was the largest ever recorded in Japan's history. The earthquake generated a massive tsunami, which reached a maximum height of $9.3 \mathrm{~m}$. This disaster led to 15,859 deaths and 3,021 missing people, with more than $90 \%$ of deaths caused by drowning and $65 \%$ of deceased individuals being over the age of 60 . Approximately, 100,000 structures were demolished and 6,000 were partially destroyed [1].

The devastating nature of disasters and their aftermath are known to cause psychological distress in affected individuals $[2,3]$. There have been growing numbers of studies concerning post-disaster mental distress, including posttraumatic stress disorder (PTSD), depression, and suicidality [4, 5]. These studies suggest that mental health care is required at an early stage following a disaster. In regards to the Great East Japan Earthquake, many activities attributed to mental health care teams have been reported, with a total of 3,498 mental health professionals having provided care within 
disaster-stricken areas [6-10]. It is thought that suicide rates in disaster-stricken areas may increase due to disaster-related mental distress, which is significantly associated with mental health problems and suicidal ideation among the general population [11-14]. However, previous studies in Japan relating to the Hanshin-Awaji and Niigata-Chuetsu earthquakes reported decreased male suicide rates for two to three years following these disasters, while female suicide rates increased or did not change significantly $[15,16]$. Based on this, it was assumed that changing suicide rates in disasterstricken areas of the Great East Japan Earthquake would exhibit a similar trend to those reported in previous domestic studies. However, few reports are available that detail factors associated with such disasters, making it difficult to determine how these events affect suicide rates.

To implement effective suicide prevention measures after disasters, this study aimed to (1) observe changes in suicide rates in disaster-stricken and neighboring areas following the Great East Japan Earthquake and (2) examine associations between suicide rates and related factors.

\section{Materials and methods}

The Great East Japan Earthquake occurred at 14:46 Japan Standard Time (JST) on March 11, 2011. The maximum seismic intensity level reached 7 near the epicenter (Fig. 1). In addition, the ensuing tsunami caused enormous damage to the Pacific coast, specifically in Iwate, Miyagi, and Fukushima Prefectures in the Tohoku region. In addition to these areas, Hokkaido and other prefectures of the Tohoku and Kanto region, including Tokyo, were damaged by the earthquake, with several casualties. However, the death toll and number of missing individuals

\begin{tabular}{|c|c|c|c|c|c|}
\hline \multicolumn{3}{|c|}{ Disaster-stricken } & \multicolumn{3}{|c|}{ Neighboring (control) } \\
\hline Pref. & $\begin{array}{l}\text { Population } \\
\text { (million) }\end{array}$ & $\begin{array}{c}\text { Age }>65 \\
(\%)\end{array}$ & Pref. & $\begin{array}{l}\text { Population } \\
\text { (million) }\end{array}$ & $\begin{array}{c}\text { Age }>65 \\
(\%)\end{array}$ \\
\hline Iwate & 1.30 & 27.9 & Aomori & 1.35 & 27.0 \\
\hline Miyagi & 2.32 & 22.9 & Akita & 1.06 & 30.7 \\
\hline Fukushima & 1.96 & 26.1 & Yamagata & 1.15 & 28.3 \\
\hline
\end{tabular}

Annual estimated population data (Oct. 1, 2012)

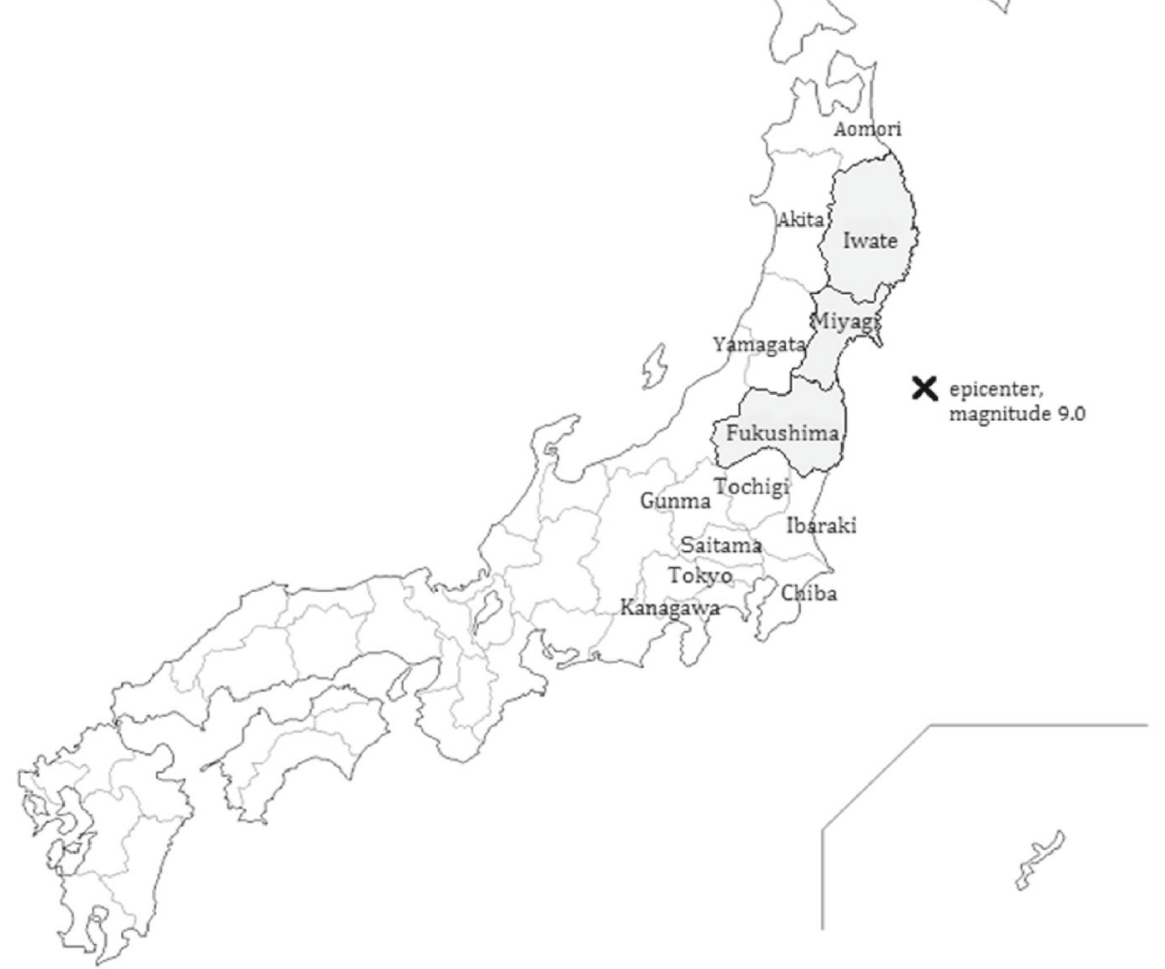

Fig. 1 Earthquake epicenter and disaster-stricken and neighboring (control) areas. The Great East Japan Earthquake occurred on March 11, 2011, with a magnitude of 9.0 and an epicenter approximately $130 \mathrm{~km}$ off the shore of Sanriku and east-southeast of the Ojika
Peninsula. The disaster-stricken area was defined as the region comprising Iwate, Miyagi, and Fukushima Prefectures. The control area was defined as the region comprising Aomori, Akita, and Yamagata Prefectures 
Table 1 The death toll and number of missing individuals in the Great East Japan Earthquake

\begin{tabular}{llrr}
\hline Regions & Prefectures & Death tolls & $\begin{array}{l}\text { Missing } \\
\text { individuals }\end{array}$ \\
\hline Hokkaido & Hokkaido & 1 & 0 \\
Tohoku Region & Iwate & $\mathbf{4 , 6 7 1}$ & $\mathbf{1 , 2 2 2}$ \\
& Miyagi & $\mathbf{9 , 5 1 7}$ & $\mathbf{1 , 5 8 1}$ \\
& Fukushima & $\mathbf{1 , 6 0 5}$ & $\mathbf{2 1 4}$ \\
& Aomori & 3 & 1 \\
& Akita & 0 & 0 \\
Kanto & Yamagata & 2 & 0 \\
& Ibaraki & 24 & 1 \\
& Tochigi & 4 & 0 \\
& Gunma & 1 & 0 \\
& Saitama & 0 & 0 \\
& Chiba & 20 & 2 \\
& Tokyo & 7 & 0 \\
& Kanagawa & 4 & 0 \\
\hline
\end{tabular}

As of 30 May 2012

Cabinet Office, Government of Japan. White paper on Disaster Management

within Iwate, Miyagi, and Fukushima Prefectures accounted for more than $99 \%$ of the total casualties (white paper on disaster management) (Table 1) [1]. Therefore, for this study, the disaster-stricken area was defined as the region comprising Iwate, Miyagi, and Fukushima Prefectures, and the neighboring (control) area was defined as the region comprising Aomori, Akita, and Yamagata Prefectures, based on the inclusion of these prefectures in the Tohoku region, which also includes the disaster-stricken areas. Notably, the populations and proportions of elderly residents in neighboring (control) areas did not differ greatly from those in disaster-stricken areas (Fig. 1). Changes in suicide rates were observed during each of the 48 months from March 2009 to February 2013.

To evaluate associations between suicide rates and related factors, the following economic variables were used: monthly number of bankruptcy cases per 100,000 people and monthly ratio of effective job offers. After the 2008 global economic crisis, male suicide rates increased in 2009 in European and American countries [17]. Since economic trends are thought to be intimately and immediately related to suicide rates, we chose these variables as economic factors potentially related to changing suicide rates.

Data sets

Monthly suicide data (ICD-10 codes X60-X84) were collected both nationally and across six prefectures in the disaster-stricken and control areas. Data were provided by the Ministry of Health, Labor, and Welfare [18]. Annual estimated population data were also collected annually on October 1st for each prefecture by the Ministry of Internal Affairs and Communications Statistics Bureau [19]. To more accurately observe changes in suicide rates, this study used a 12-month centralized moving average of suicide rates, to remove seasonal differences.

These economic variables were chosen based on their use by local governments as main indicators of economic status, as well as the ability to obtain these data every month. Moreover, previous domestic studies reported associations between suicide rates and the number of job applicants and bankruptcy rates [20, 21]. The numbers of bankruptcy cases were obtained from Tokyo Shoko Research, Ltd., and the ratios of effective job offers were reported by local employment security offices. Employment security offices included public facilities in which job introductions and job application registrations are conducted. Numbers of bankruptcy cases were adjusted for seasonal variation using a 12-month centralized moving average. The ratios of effective job offers were already adjusted for seasonal variation.

Monthly suicide data and economic data (Table 2) were obtained from open-access websites as unlinkable, anonymous data. According to epidemiological research guidelines set forth by the Ministry of Education, Culture, Sports, Science and Technology and the Ministry of Health, Labor and Welfare, ecological studies are exempt from ethical review. Accordingly, review by an ethics committee was not necessary.

\section{Data analysis}

Forty-eight months of suicide rate data were divided into pre-disaster (March 2009 to February 2011) and postdisaster (March 2011 to February 2013) periods. Changes in suicide rates from the previous month were compared using a Poisson distribution test. Univariate and multiple regression analyses were performed using monthly pre- and post-disaster suicide rates as dependent variables, and economic factors as independent variables. Before univariate regression analysis was performed, monthly suicide rates and economic variables were converted by logarithmic transformation. Subsequently, differences from the previous month [difference $=\log \left(X_{t}\right)-\log \left(X_{t-1}\right)$ ] were calculated. Because economic data often follow a random walk and show non-stationarity, these data have undesirable properties for regression analysis. Statistical significance was evaluated using two-sided, design-based tests with a $5 \%$ level of significance. Statistical analyses were performed using Ekuseru-Toukei 2012 (Social Survey Research Information Co., Ltd. Tokyo, Japan). 
Table 2 Characteristic of monthly suicide rates and economic variables
$S D$ standard deviation, Disasterstricken areas Iwate, Miyagi, and Fukushima, Neighboring (control) areas Aomori, Akita, and Yamagata

\begin{tabular}{|c|c|c|c|c|}
\hline & \multirow{2}{*}{\multicolumn{2}{|c|}{$\begin{array}{l}\text { Suicide rates per } 100,000 \\
\text { populations (male) } \\
\text { Mean (SD) }\end{array}$}} & \multirow{2}{*}{\multicolumn{2}{|c|}{$\begin{array}{l}\text { Suicide rates per 100,000 } \\
\text { populations (female) }\end{array}$}} \\
\hline & & & & \\
\hline & $\begin{array}{l}\text { Pre-disaster } \\
(2009.3-2011.2)\end{array}$ & $\begin{array}{l}\text { Post-disaster } \\
(2011.3-2013.2)\end{array}$ & $\begin{array}{l}\text { Pre-disaster } \\
(2009.3-2011.2)\end{array}$ & $\begin{array}{l}\text { Post-disaster } \\
(2011.3-2013.2)\end{array}$ \\
\hline $\begin{array}{l}\text { Disaster-stricken } \\
\text { areas }\end{array}$ & $33.2(2.4)$ & $27.5(1.6)$ & $11.5(0.4)$ & $11.3(0.9)$ \\
\hline $\begin{array}{l}\text { Neighboring } \\
\text { (control) areas }\end{array}$ & $38.4(2.5)$ & $32.1(1.6)$ & $14.0(0.5)$ & $12.5(0.4)$ \\
\hline \multirow[t]{4}{*}{ National } & $28.9(1.0)$ & $26.0(1.0)$ & $11.0(0.3)$ & $10.8(0.6)$ \\
\hline & \multicolumn{2}{|c|}{$\begin{array}{l}\text { Number of bankruptcy case } \\
\text { per } 100,000 \text { populations }\end{array}$} & \multicolumn{2}{|c|}{ Ratio of effective job offers } \\
\hline & \multicolumn{2}{|l|}{ Mean (SD) } & \multicolumn{2}{|l|}{ Mean (SD) } \\
\hline & $\begin{array}{l}\text { Pre-disaster } \\
(2009.3-2011.2)\end{array}$ & $\begin{array}{l}\text { Post-disaster } \\
(2011.3-2013.2)\end{array}$ & $\begin{array}{l}\text { Pre-disaster } \\
(2009.3-2011.2)\end{array}$ & $\begin{array}{l}\text { Post-disaster } \\
(2011.3-2013.2)\end{array}$ \\
\hline $\begin{array}{l}\text { Disaster-stricken } \\
\text { areas }\end{array}$ & $0.55(0.06)$ & $0.30(0.07)$ & $0.41(0.07)$ & $0.84(0.23)$ \\
\hline $\begin{array}{l}\text { Neighboring } \\
\text { (control) areas }\end{array}$ & $0.62(0.08)$ & $0.45(0.03)$ & $0.38(0.07)$ & $0.63(0.10)$ \\
\hline National & $0.93(0.07)$ & $0.81(0.33)$ & $0.50(0.06)$ & $0.74(0.08)$ \\
\hline
\end{tabular}

\section{Results}

Changes in suicide rates in disaster-stricken and control areas

Changes in suicide rates in disaster-stricken and control areas are shown in Fig. 2. Pre-disaster male suicide rates in both areas were higher than the national average. Female suicide rates in disaster-stricken areas varied similarly, as compared to the national average. Post-disaster male suicide rates in disaster-stricken areas decreased during the 24 months following the earthquake, despite a slight increase in suicide rates during the fifth through seventh months after the earthquake. In contrast, post-disaster female suicide rates increased following the earthquake with no significant change (suicide rates per 100,000 of 14.3 in Feb 2011 vs. 14.9 in Mar 2011, Poison distribution test, $p=0.482$ ) and remained high for 7 months, while suicide rates in control areas decreased. Postdisaster male suicide rates decreased during the first 12 months following the earthquake not only in disasterstricken areas, but also in control areas. However, this rate increased during post-disaster months 13-20 in control areas.

Associations between pre- and post-disaster suicide rates and economic variables

Changes in economic variables in both disaster-stricken and control areas are shown in Fig. 3. Associations between preand post-disaster suicide rates and economic variables are shown in Tables 3 and 4. Correlations between monthly suicide rates and economic variables were examined based on each variable to confirm multicollinearity. As a result, all correlation coefficients between the variables were below 0.50 (data not shown). In these univariate and multiple regression models, if the regression coefficient is positive, suicide rates would increase under situations increasing values of economic factors. And if the coefficient is negative, the rates would decrease under situations increasing the values. Univariate regression analysis showed that the number of bankruptcy cases per 100,000 people $(\beta=0.411, p=0.046)$, and the ratio of effective job offers (Regression coefficient $\beta=-0.467, p=0.022$ ), were only significantly associated with male suicide rates in post-disaster control areas. No significant associations were found between economic variables and monthly suicide rates for males in disaster-stricken areas, or females in both areas. Multiple regression analysis showed that the number of bankruptcy cases per 100,000 people $(\beta=0.386, p=0.038)$ and ratio of effective job offers $(\beta=-0.445, p=0.018)$ were significantly associated with male suicide rates in control areas (coefficient of determination, $R^{2}=0.366$ ). However, for males in disasterstricken areas and females in both areas, multiple regression analysis revealed no significant associations between economic variables and monthly suicide rates.

\section{Discussion}

In this study, we found that male suicide rates in disasterstricken areas decreased more than those in control areas 
Fig. 2 Changes in suicide rate trends in disaster-stricken and neighboring (control) areas. Suicide rate trends in disasterstricken and control areas are shown. Suicide rates are depicted per 100,000 people. The down arrow corresponds to the occurrence of the Great East Japan Earthquake
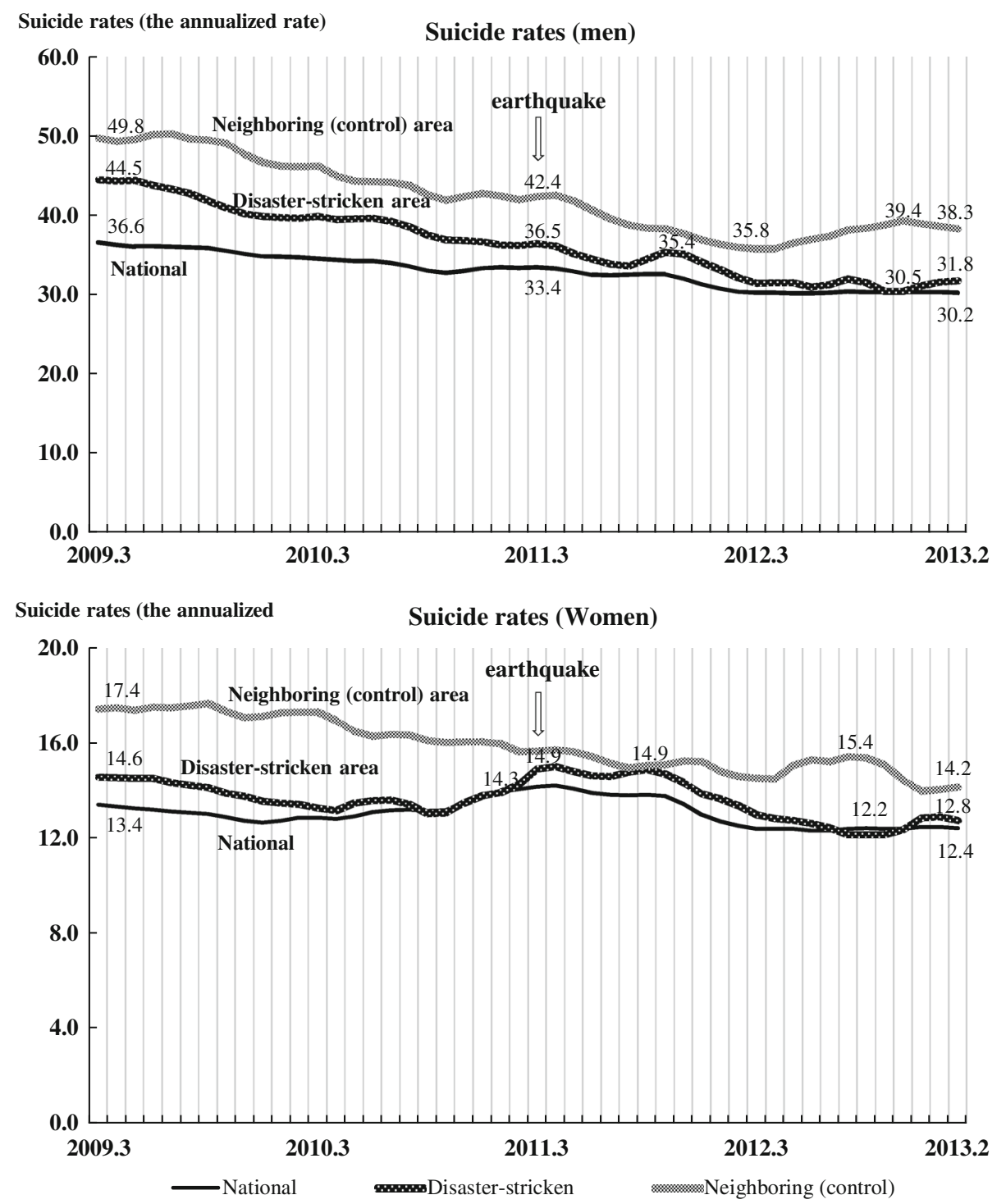

Suicide rates (annualized rate): monthly suicide number/population* 100,000* 12

Disaster-stricken areas: Iwate, Miyagi, and Fukushima Neighboring (control) areas: Aomori, Akita, and Yamagata during the 24 months following the Great East Japan Earthquake, reaching the same level as the national average. In contrast, female suicide rates in disaster-stricken areas increased with no significant changes following the earthquake, while suicide rates in control areas decreased. Gender-dependent changes in suicide rates in disasterstricken areas as observed in the present study were also consistent with those from previous studies in Kobe City and Niigata-Chuetsu [15, 16]. A previous study, conducted in Kobe City, Japan (the disaster-stricken area of the 1995 Hanshin-Awaji Earthquake), reported that male suicide rates decreased significantly two years post-disaster, whereas female suicide rates did not significantly change [15]. Likewise, male suicide rates in the Chuetsu region of Niigata decreased, while female suicide rates increased, during the 3-year period following the 2004 NiigataChuetsu Earthquake [16]. Moreover, studies in Taiwan revealed that suicide rates increased significantly following a major earthquake, with female suicide rates increasing immediately, and male suicide rates showing a delayed increase [22]. Gender differences observed in post-disaster suicide rates have important implications. Notably, female suicide rates increased in disaster-stricken areas during the first 7 months following the Great East Japan Earthquake. In general, women have a lower risk of committing suicide than men, but could potentially become a high-risk group after earthquakes. The findings of this study suggest the importance of considering gender differences in suicide rates when implementing suicide prevention measures after disasters. 
Fig. 3 Changes in economic variables in disaster-stricken and neighboring (control) areas. The number of bankruptcy cases per 100,000 people and ratio of effective job offers in disasterstricken and control areas are shown. The down arrow corresponds to the occurrence of the Great East Japan Earthquake
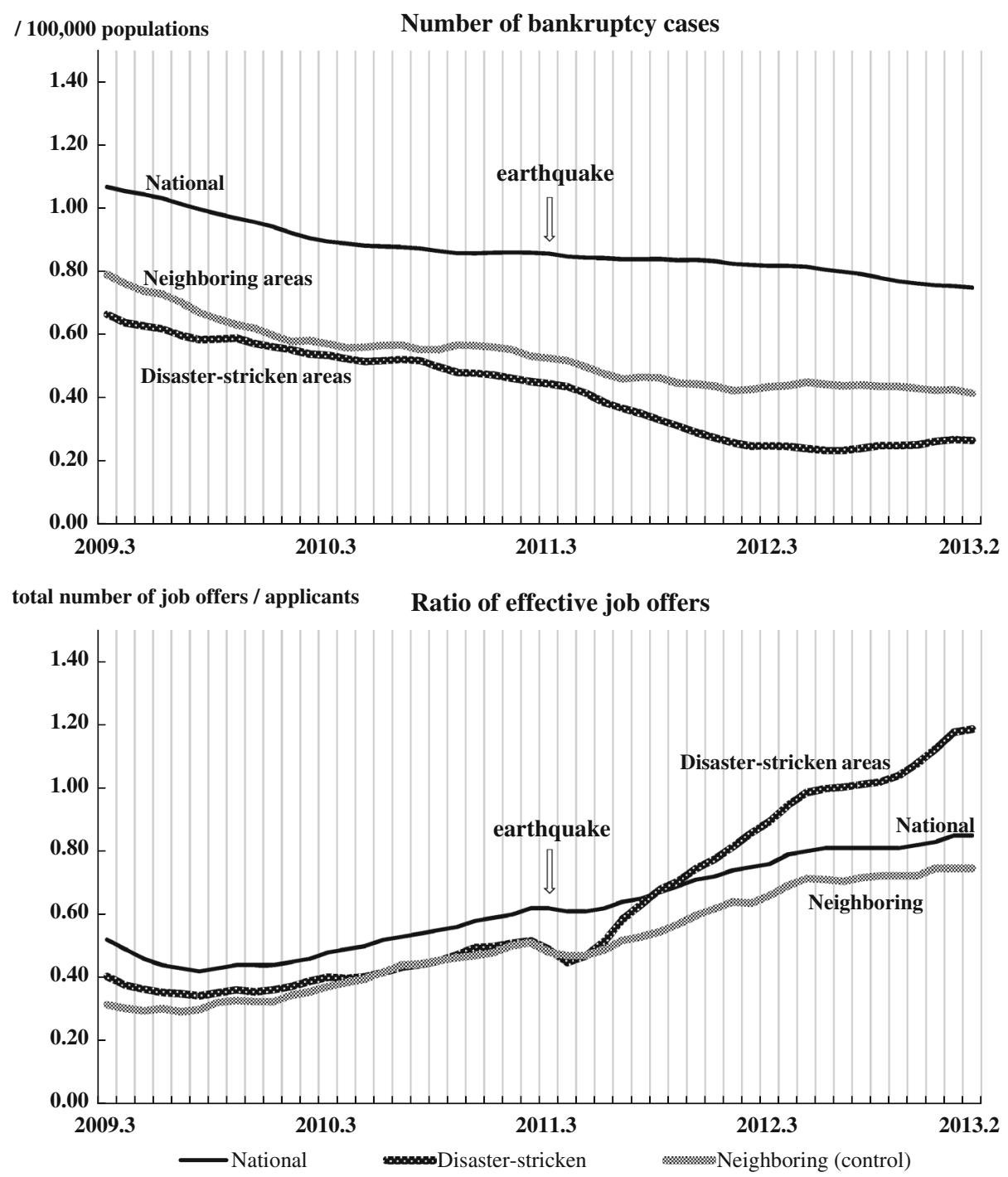

Disaster-stricken areas: Iwate, Miyagi, and Fukushima Neighboring (control) areas: Aomori, Akita, and Yamagata

Table 3 Univariate regression analysis between suicide rates and economic variables

\begin{tabular}{|c|c|c|c|c|c|c|c|c|}
\hline & \multicolumn{4}{|c|}{ Number of bankruptcy case per 100,000 populations } & \multicolumn{4}{|c|}{ Ratio of effective job offers } \\
\hline & \multicolumn{2}{|c|}{$\begin{array}{l}\text { Pre-disaster } \\
(2009.3-2011.2)\end{array}$} & \multicolumn{2}{|c|}{$\begin{array}{l}\text { Post-disaster } \\
(2011.3-2013.2)\end{array}$} & \multicolumn{2}{|c|}{$\begin{array}{l}\text { Pre-disaster } \\
(2009.3-2011.2)\end{array}$} & \multicolumn{2}{|c|}{$\begin{array}{l}\text { Post-disaster } \\
(2011.3-2013.2)\end{array}$} \\
\hline & $\beta$ & $p$-value & $\beta$ & $p$-value & $\beta$ & $p$-value & $\beta$ & $p$-value \\
\hline \multicolumn{9}{|l|}{ Men } \\
\hline Disaster-stricken areas & 0.037 & 0.862 & 0.325 & 0.121 & -0.234 & 0.272 & -0.200 & 0.348 \\
\hline Neighboring (control) areas & 0.046 & 0.832 & 0.411 & 0.046 & -0.032 & 0.882 & -0.467 & 0.022 \\
\hline \multicolumn{9}{|l|}{ Women } \\
\hline Disaster-stricken areas & 0.206 & 0.333 & 0.358 & 0.086 & 0.175 & 0.413 & -0.271 & 0.201 \\
\hline Neighboring (control) areas & -0.180 & 0.399 & 0.327 & 0.119 & -0.137 & 0.522 & -0.043 & 0.841 \\
\hline
\end{tabular}

$\beta$ Standardized partial regression coefficient, Disaster-stricken areas Iwate, Miyagi, and Fukushima, Neighboring (control) areas Aomori, Akita, and Yamagata

Italic: $p<0.05$ 
Table 4 Multiple regression analysis between suicide rates and economic variables

\begin{tabular}{|c|c|c|c|c|c|c|c|c|c|c|}
\hline & \multicolumn{5}{|c|}{ Pre-disaster (2009.3-2011.2) } & \multicolumn{5}{|c|}{ Post-disaster (2011.3-2013.2) } \\
\hline & \multicolumn{2}{|c|}{$\begin{array}{l}\text { Number of bankruptcy } \\
\text { case per } 100,000 \\
\text { populations }\end{array}$} & \multicolumn{2}{|c|}{$\begin{array}{l}\text { Ratio of effective } \\
\text { job offers }\end{array}$} & \multirow[t]{2}{*}{$R^{2}$} & \multicolumn{2}{|c|}{$\begin{array}{l}\text { Number of bankruptcy } \\
\text { case per } 100,000 \\
\text { populations }\end{array}$} & \multicolumn{2}{|c|}{$\begin{array}{l}\text { Ratio of effective } \\
\text { job offers }\end{array}$} & \multirow[t]{2}{*}{$R^{2}$} \\
\hline & $\beta$ & $p$-value & $\beta$ & $p$-value & & $\beta$ & $p$-value & $\beta$ & $p$-value & \\
\hline \multicolumn{11}{|l|}{ Men } \\
\hline Disaster-stricken areas & 0.181 & 0.450 & -0.316 & 0.193 & 0.080 & 0.291 & 0.207 & -0.086 & 0.705 & 0.112 \\
\hline Neighboring (control) areas & 0.062 & 0.790 & -0.051 & 0.825 & 0.004 & $\underline{0.386}$ & 0.038 & $\underline{-0.445}$ & 0.018 & $\underline{0.366}$ \\
\hline \multicolumn{11}{|l|}{ Women } \\
\hline Disaster-stricken areas & 0.160 & 0.510 & 0.103 & 0.671 & 0.051 & 0.297 & 0.189 & -0.154 & 0.490 & 0.148 \\
\hline Neighboring (control) areas & -0.152 & 0.506 & -0.090 & 0.693 & 0.040 & 0.325 & 0.130 & -0.024 & 0.907 & 0.107 \\
\hline
\end{tabular}

$\beta$ Standardised partial regression coefficient, $R^{2}$ coefficient of determination, Disaster-stricken areas Iwate, Miyagi, and Fukushima, Neighboring (control) areas Aomori, Akita, and Yamagata

Italic: $p<0.05$

To investigate factors related to suicide rates, the association between monthly suicide rates and economic variables was examined. This analysis revealed that the number of bankruptcy cases per 100,000 people and ratio of effective job offers were only significantly associated with male suicide rates in post-disaster control areas. Aihara et al. reported that the number of job applicants, bankruptcy rate, and amount of savings per household were significantly associated with male suicide rates [18]. Furthermore, Yamasaki et al. reported that socioeconomic variables, such as low income or unemployment, were important determinants of suicide rates among Japanese men [19]. A previous study on the Niigata-Chuetsu Earthquake reported that economic conditions in the disaster area improved due to temporary government financial aid [16]. Economic conditions following the Great East Japan Earthquake, including higher ratios of effective job offers and lower numbers of bankruptcy cases, improved in both disaster-stricken and control areas due to the emerging demand for disaster-recovery services (i.e., construction and waste disposal) [23]. Given that a stable economic status is a protective factor against suicide, increasing effective job offers and decreasing bankruptcy cases were assumed to have affected the suicide rates. However, the goodness of fit in this regression model was low (male, $R^{2}=0.112$; female $R^{2}=0.148$ ) in the disasterstricken area. Thus, post-disaster suicide rates in disasterstricken areas may be associated with other factors, such as mental health care activity, which may have a greater impact on changes in suicide rates.

The present study has several limitations worth noting. First, the disaster-stricken and control areas had the highest suicide rates in Japan. In this context, suicide rates in Japan increased sharply in 1988 and have remained relatively high ever since. Given this trend, many continuous suicide prevention measures had already been implemented for a decade before the earthquake occurred. These efforts may have influenced the observed changes in suicide rates. Despite the devastating disaster, an important point is that male suicide rates in the disaster-stricken area decreased continuously after the earthquake occurred with rates eventually reaching the national average. Secondly, some earthquake victims were evacuated from the disasterstricken areas due to the earthquake. This relocation may have affected the findings by changing post-disaster suicide rates in each prefecture. However, the Reconstruction Agency reported that $75 \%$ of earthquake victims had been evacuated within Iwate, Miyagi and Fukushima Prefectures, as of February 2013 [24]. Therefore, the findings of this study can only be considered reliable to a certain extent. Thirdly, additional variables may be associated with changes in suicide rates. It can thus be assumed that social factors such as voluntary community networks, relationships based on trust $[25,26]$, mental health care services provided to the disaster-stricken population by mental health specialists, and other public health services, are protective factors against suicide. Unfortunately, no quantitative monthly data on these variables were available at the prefectural level. Fourthly, the economic variables selected in this study may not be adequate; however, we chose these variables because they could be obtained on a monthly basis at the prefectural level. Lastly, the ecological study design did not allow the determination of the cause of changes in suicide rates. Certainly, mental and physical health condition, past history of suicide attempts, lifestyle, economic status, and others are important risk factors for suicide [27]; unfortunately, these data for individuals were not readily available. Further studies, which take into consideration such data, will be needed to examine the cause of changing suicide rates. 
In conclusion, post-disaster suicide rates in disasterstricken areas decreased among men during the 24 months following the earthquake, and increased for females during the first seven post-disaster months. Economic variables (number of bankruptcy cases and ratio of effective job offers) were not significantly associated with suicide rates in disaster-stricken areas. Despite the limitations of the present study, the findings regarding gender differences in post-disaster suicide rates will contribute to public health efforts aimed at post-disaster suicide prevention. Given that this study did not find an association between changing suicide rates and the selected economic variables, further studies will be needed to clarify the reasons underlying changing suicide rates. Previous domestic studies, which showed decreased male suicide rates following devastating earthquakes, are limited to a period of two to three years after a disaster $[15,16]$, and have reported that suicide rates increase after 3 years in both genders [15]. Long-term suicide rate trends must be tracked carefully to implement adequate suicide prevention measures.

Acknowledgments This study was supported by a Grant from the Sendai City Public Health Research Project.

Conflict of interest The authors have no conflicts of interest to declare.

\section{References}

1. Cabinet Office, Government of Japan. White paper on Disaster Management. Saeki Printing Co., Ltd., Tokyo, 2011.

2. Murphy SA. Status of natural disaster victims' health and recovery 1 and 3 years later. Res Nurs Health. 1986;9:331-40.

3. Kiliç C, Ulusoy M. Psychological effects of the November 1999 earthquake in Turkey: an epidemiological study. Acta Psychiatr Scand. 2003;108:232-8.

4. Wu HC, Chou FH, Su CY, Tsai KY, Ou-Yang WC, Su TT, et al. Survey of quality of life and related risk factors for a Taiwanese village population 3 years post-earthquake. Aust NZJ Psychiatry. 2006;40:355-61.

5. Suzuki Y, Tsutsumi A, Fukasawa M, Honma H, Someya T, Kim $\mathrm{Y}$, et al. Prevalence of mental disorders and suicidal thoughts among community-dwelling elderly adults 3 years after the niigata-chuetsu earthquake. J Epidemiol. 2011;21:144-50.

6. Ministry of Health, Labor and Welfare. The damage situation and its about correspondence of the great East Japan earthquake (the 116th report). http://www.mhlw.go.jp/jishin/joukyoutaiou.html (2012.2.24)

7. Kim Y. Great East Japan earthquake and early mental-health-care response. Psychiatry Clin Neurosci. 2011;65:539-48.

8. Takeda M. Mental health care and East Japan Great Earthquake. Psychiatry Clin Neurosci. 2011;65:207-12.

9. Suzuki Y, Kim Y. The great east Japan earthquake in 2011; toward sustainable mental health care system. Epidemiol Psychiatr Sci. 2012;21:7-11.
10. Matsuoka $\mathrm{H}$. The Great East Japan earthquake and mid- and longterm prospect for mental health and welfare in Miyagi Prefecture. Seishin Shinkeigaku Zasshi. 2012;114:218-22 (in Japanese).

11. Lee S, Fung SC, Tsang A, Liu ZR., Huang YQ, He YL, et al. Lifetime prevalence of suicide ideation, plan, and attempt in metropolitan China. Acta Psychiatr Scand 2007; 116: 429-37.

12. Bromet EJ, Havenaar JM, Tintle N, Kostyuchenko S, Kotov R, Gluzman S, et al. Suicide ideation, plans and attempts in Ukraine: findings from the Ukraine World Mental Health Survey. Psychol Med. 2007;37:807-19.

13. Ono Y, Kawakami N, Nakane Y, Nakamura Y, Tachimori H, Iwata $\mathrm{N}$, et al. Prevalence of and risk factors for suicide-related outcomes in the world health organization world mental health surveys japan. Psychiatry Clin Neurosci. 2008;62:442-9.

14. Orui M, Kawakami N, Iwata N, Takeshima T, Fukao A, et al. Lifetime prevalence of mental disorders and its relationship to suicidal ideation in a Japanese rural community with high suicide and alcohol consumption rates. Environ Health Prev Med. 2011;16:384-9.

15. Nishio A, Akazawa K, Shibuya F, Abe R, Nushida H, Ueno Y, et al. Influence on the suicide rate two years after a devastating disaster: A report from the 1995 Great Hanshin-Awaji Earthquake. Psychiatry Clin Neurosci. 2009;63:247-50.

16. Hyodo K, Nakamura K, Oyama M, Yamazaki O, Nakagawa I, Ishigami $\mathrm{K}$, et al. Long-term suicide mortality rates decrease in men and increase in women after the niigata-chuetsu earthquake in Japan. Tohoku J Exp Med. 2010;220:149-55.

17. Chang SS, Stuckler D, Yip P, Gunnell D. Impact of 2008 global economic crisis on suicide: time trend study in 54 countries. BMJ. 2013;347:1-15.

18. Ministry of Health, Labor and Welfare. Vital statistics. http://www. mhlw.go.jp/toukei/list/81-1a.html (2012.7.26) (in Japanese).

19. Statistics Bureau, the Ministry on Internal Affairs and Communications. Population Estimates. http://www.stat.go.jp/data/jinsui/ whatsnew.htm (2012.3.21) (in Japanese).

20. Aihara H, Iki M. An ecological study of the relations between the recent high suicide rates and economic and demographic factors in Japan. J Epidemiol. 2003;13:56-61.

21. Yamasaki A, Araki S, Sakai R, Yokoyama K, A. Scott Voorhees KA, et al. Suicide mortality of young, middle-aged and elderly males and females in Japan for the years 1953-1996: Time series analysis for the effects of unemployment, female labour force, young and aged population, primary industry and population density. Industrial Health 2008; 46: 541-9.

22. Paul Y. Effects of an earthquake on suicide rates in Nantou, Taiwan. Br J Psychiatry. 2009;194:190.

23. Economic and Social Analysis Institute, Cabinet office, government of Japan. Regional economics 2012. http://www5.cao.go.jp/ $\mathrm{j}$-j/cr/cr12/chr12_index-pdf.html (2012.11.2) (in Japanese).

24. Reconstruction Agency, Current Situations of Evacuees in the aftermath of the Earthquake http://www.reconstruction.go.jp/ topics/001169.html (2013.2.15) (in Japanese).

25. Kelly BD, Davoren M, Mhaoláin AN, Breen EG, Casey P, et al. Social capital and suicide in 11 European countries: an ecological analysis. Soc Psychiatry Psychiatr Epidemiol. 2009;44:971-7.

26. Okamoto M, Kawakami N, Kido Y, Sakurai K. Social capital and suicide: an ecological study in Tokyo, Japan. Environ Health Prev Med. 2013;18:306-12.

27. Ping Q, Esben A, Preben BM. In Prevention and treatment of suicidal behavior: from science to practice. Factors contributing to suicide: the epidemiological evidence from large-scale registers. Oxford University Press, Oxford, 2005. 